\title{
A Prospective Study of Efficacy of Selective Estrogen Receptor Modulator (Serm) In Aberration of Normal Development and Involution of Breast (Andi)
}

\author{
Dr. S.S. Meera ${ }^{1}$ M.S., Prof. N. Tamilselvan ${ }^{2}$ M.S., Dr. P. Satheeshkumar ${ }^{3}$, Dr.V. \\ Rishigowtham. \\ ${ }^{1}$ (Assistant Professor of General Surgery, Government Mohan Kumaramangalam Medical College, Salem, \\ Tamilnadu, India.) \\ ${ }^{2}$ (Associate Professor of General Surgery, Government Mohan Kumaramangalam Medical College, Salem, \\ Tamilnadu, India.) \\ 3,4 (Post Graduate, Department of General Surgery, Government Mohan Kumaramangalam Medical College, \\ Salem, Tamilnadu, India.
}

\begin{abstract}
A better understanding of benign breast disorders comes from a comprehensive framework 'Aberrations of normal development and Involution' (ANDI) - under which most of the breast complaints can be explained. Benign Breast disorders can be noted as 'Universal phenomenon' in all ages of women causing physical and psychological distress to the patient. ANDI is an umbrella term used to describe the breast disorders that arise due to minor aberrations of the normal process of development, cyclical hormonal response and Involution. Though there have been many drugs used previously, their side-effects overwhelmed the benefits. So, a drug with minimal side-effects and maximum efficacy is the need of the hour in relieving the symptoms and promoting regression of ANDI.This has encouraged this study of efficacy of a newer selective estrogen receptor modulator in ANDI. Our study claims that Ormeloxifen is significantly effective in Aberration of development and cyclical changes of Breast with targeted efficacy profile, fewer adverse effects and lower economical burden, but efficacy is not proved in Aberrations of involution of breast.
\end{abstract}

Keywords: ANDI, Ormeloxifen

\section{Introduction}

Almost all the benign breast disorders come under the umbrella of 'Aberrations of normal development and Involution' (ANDI) -under which most of the breast complaints can be explained. Benign Breast disorders can be noted as 'Universal phenomenon' in all ages of women causing physical and psychological distress to the patient. ANDI is a comprehensive term used to describe the breast disorders that arise due to minor aberrations of the normal process of development, cyclical hormonal response and Involution. Though many drugs were tried and used in the past their side-effects overwhelmed the benefits. So, a drug with minimal side-effects and maximum efficacy is the need of the hour in relieving the symptoms and promoting regression of ANDI. This has encouraged ourselves to take up this study which aims at evaluating the efficacy of a newer selective estrogen receptor modulator (ORMELOXIFEN) in ANDI.

\section{Aims And Objectives:}

To assess the efficacy of Ormeloxifen, a selective estrogen receptor modulator in regression of ANDI.

III.1. Study type: Interventional

\section{Materials And Methods}

III.2. Study design: Non - randomized Prospective study.

III.3. Study group: Over one year, 100 patients with breast symptoms such as mastalgia, benign lumps, Cysts, nodularity --attending the General Surgery department of GMK medical college hospital, Salem were considered as data source. Individuals who fulfilled the inclusive and exclusive criteria were enrolled in the study.

III.4. Inclusion criteria:

1. Age : 15 to 55 years

2. Sex : Female

3. Mastalgia, cysts, benign lumps (Fibroadenoma less than $3 \mathrm{cms}$ in diameter), nodularity

III.5. Exclusion criteria:

1. Not willing to give consent

2. Malignancy. 
3. Fibroadenoma more than $3 \mathrm{cms}$ in diameter

4. Age more than 55 years.

\section{III.6. Study method instituted:}

Women of age group 15 to 55 years presenting to General Surgery OP with complaints of mastalgia (both cyclical and non-cyclical), nodularity, benign lumps and cysts were included in this study. Malignancy was excluded first by triple assessment (Clinical, Radiological and Histological). Ormeloxifen 60 mgs (DS) was given twice weekly for three months to all the patients enrolled in our study. A second cycle of Ormeloxifen 60 mgs once weekly was given to benign lumps who needed further regression .Mastalgia ,nodularity and lump size were assessed serially at the initial visit and bi-monthly visits. Intake of tablet and self-reporting were documented as compliance. Pain at initial visit and at subsequent visits was documented using Visual Analog Scale using a VAS ruler. It is a linear analogue 10 point scale with markings from 0 to 10 , in which,' 0 ' denotes absence of pain and' 10' denotes extreme pain. Nodularity of the Breast was documented on the Lucknow Cardiff scale in view of extent of breast involved with nodularity and extent of nodularity (consistency). This scale was documented by the same clinician for each patient at each visit to prevent observer bias. This scale is a five point ordinal scale with grades 0 to grade 4 , in which grade 0 denotes no nodularity with soft consistent breast and grade 4 denotes the maximum nodularity. Results were documented as per clinical examination, Visual Analog Scale for pain, Lucknow Cardiff scale for nodularity and Ultrasonogram for size of lumps.

III.7. Follow up: Bi-monthly follow up was done in all patients for a period of 12 weeks and then monthly follow up for next three months for all cases.

\section{Results}

Out of 100 patients included in this study, 73 patients had mastalgia with or without nodularity . 22 patients had Fibroadenoma and 5 patients had isolated benign cysts. In Mastalgia group, $85 \%$ patients had noncyclical pain and $15 \%$ had cyclical mastalgia. A VAS score of 10 was recorded by $75 \%$ patients and the other $25 \%$ patients recorded VAS score of 6 to 9 . The size of the lump in Fibroadenoma ranged from $1.5 \mathrm{cms}$ to $3 \mathrm{cms}$. Multiple Fibroadenomas in same breast were seen in 5 patients. Bilateral Fibroadenomas were seen in 3 patients. A very good response was noted in the Mastalgia and Nodularity (Fibrocystic disease) group with significant decrease in VAS scoring from 10 to 3 in first month and a decrease to $1 / 0$ in three months (Fig 1). Nodularity disappeared in almost all cases in 8 to 12 weeks from grade 4 to 0 . (Fig 2)

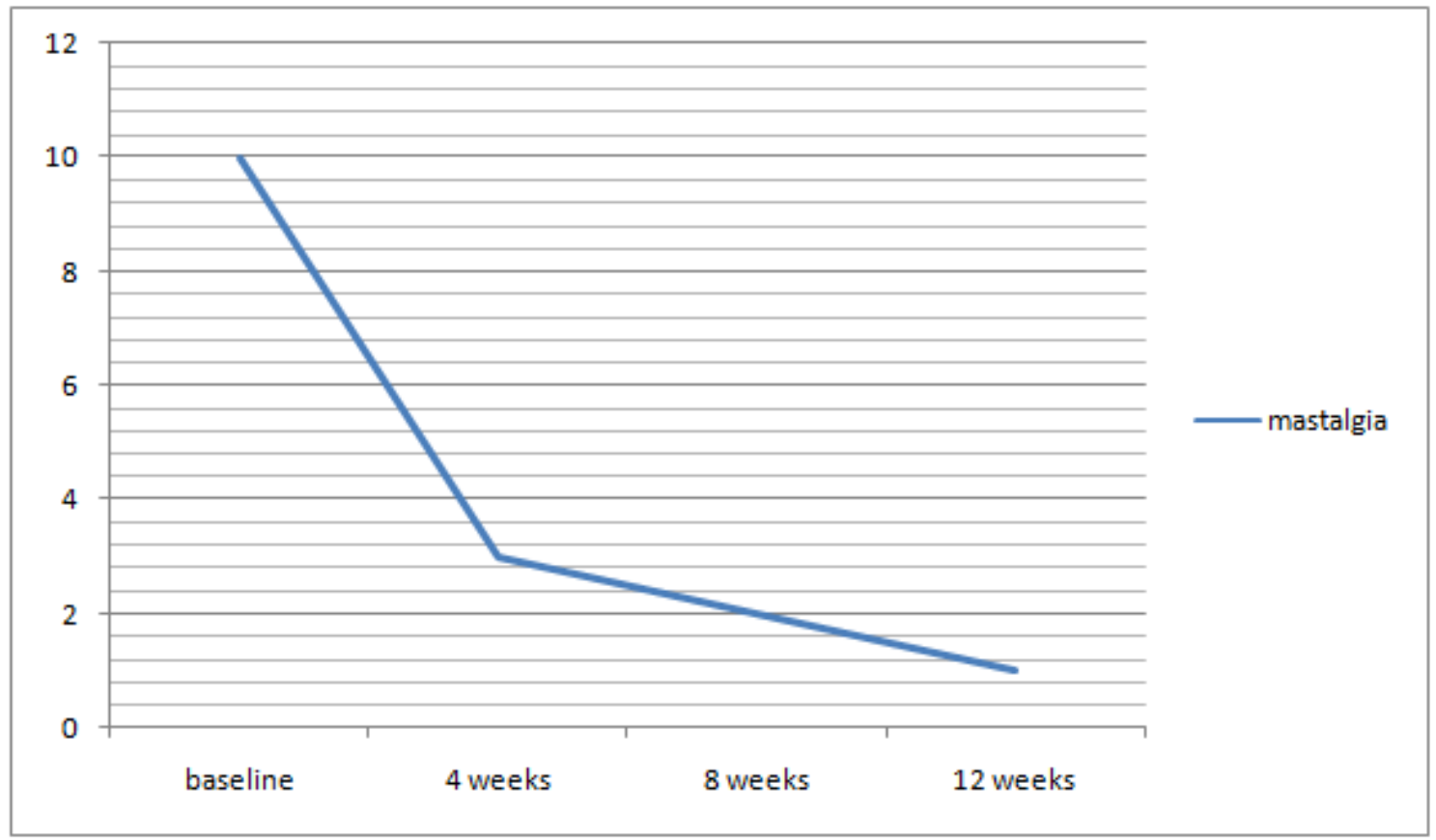

Fig 1: Assessment of Mastalgia in Ormeloxifen therapy 


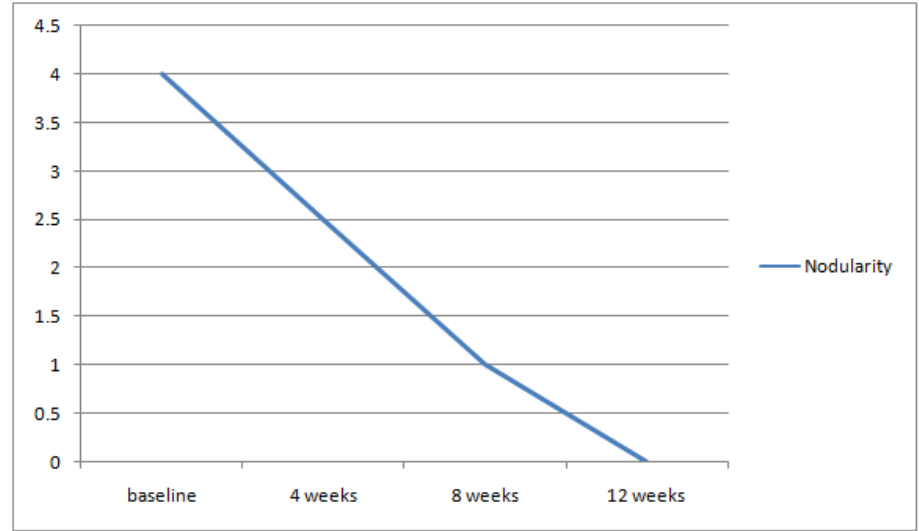

Fig 2: Assessment of Nodularity in Ormeloxifen therapy

In Fibroadenoma group, (at the end of 12 weeks) the lumps completely disappeared in $60 \%$ of the patients, $75 \%$ regression in $30 \%$ of the patients and 25 to $40 \%$ regression in $10 \%$ of the patients and these patients were followed up again with Ormeloxifen therapy $60 \mathrm{mgs}$ once weekly for next 12 weeks with complete disappearance of lumps. There was no response in Isolated Breast cysts cases (Macrocysts), but complete regression occurred in all cases if cysts were associated with nodularity (Fibrocystic disease). There was no reported allergy to the drug. There were no other complications except prolonged menstrual cycles in 10 $\%$ patients as listed in Fig 3.

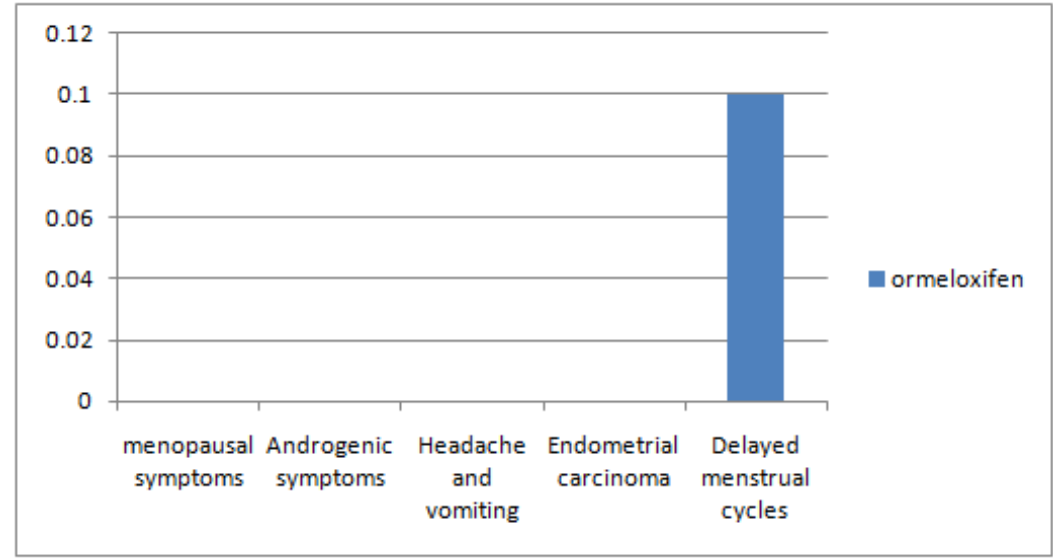

Fig 3: Complications of Ormeloxifen

So, our study brings us the ideology that Ormeloxifen is significantly effective in Aberration of development and cyclical changes, but efficacy is not documented as for as the Aberrations of involution of breast is concerned.

\section{Discussion}

ANDI was published in 1987 to categorize the benign breast symptoms under one roof, to define patient's symptoms in terms of pathogenesis, histology and clinical implications. The major anatomical unit affected in ANDI is terminal ductal unit. ANDI classification of benign breast disorders [1]:

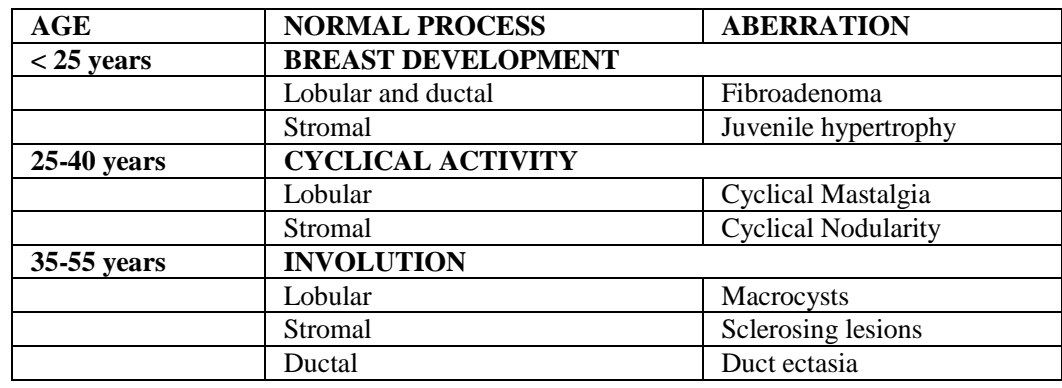

Table 1: ANDI classification 
Srivastava et al [2] conducted a meta-analysis of randomized trials in evidence based management of Mastalgia. Efficacy of Bromocriptine, Danazol, Goserelin and Tamoxifen were analysed and this meta-analysis recommended Tamoxifen as the drug of choice for treating mastalgia. But Tamoxifen causes hot flushes, perimenopausal symptoms and has significant association with endometrial carcinoma. Other drugs used in regression of benign breast symptoms are listed in Table -2 with their side effects.

\begin{tabular}{|l|l|}
\hline Drug name & Side effects \\
\hline Bromocriptine & Headache, nausea, vomiting, giddiness \\
\hline Danazol & Weight gain, hirsutism, nausea, headache, voice change, acne, decrease in size of breast \\
\hline Goserelin & Peri-menopausal symptoms, reduction in bone mass \\
\hline Tamoxifen & $\begin{array}{l}\text { Hot flushes, peri-menopausal symptoms and significant association with endometrial } \\
\text { carcinoma. }\end{array}$ \\
\hline Evening primrose oil & Abdominal pain, acne, constipation/diarrhoea, Anxiety \\
\hline
\end{tabular}

Table 2: Drugs used in ANDI

So a drug with minimal side-effects and maximum efficacy is the need for the hour in relieving the symptoms and in regression of ANDI. This has encouraged this study which aims at evaluating the efficacy of a novel selective estrogen receptor modulator in ANDI. Ormeloxifen is a novel non-steroidal, non-hormonal, selective estrogen receptor modulator-exhibiting anti-estrogen action [4]. It is a weak estrogen receptor agonist and a strong estrogen receptor antagonist and hence a selective and potent estrogen receptor modulator. It is primarily used as a weekly single dosed contraceptive or as a need oriented post-coital contraceptive [5]. This drug has been included in National Family welfare programme since 1995. Its action is estrogenic in certain areas of body like bones, and anti-estrogenic in uterus and breasts. Thus it acts as either estrogen receptor agonists or antagonists in a tissue selective manner. Its only side effect is menstrual cycle prolongation in $10 \%$ patients. The detailed description of mechanism of action at molecular level of estrogen receptors needs to be established by further research studies.

Sandeep kumar et al conducted a randomized double-blind placebo controlled trial of ormeloxifen in breast pain and nodularity and showed a significant efficacy in treatment response [3]. In our study, Ormeloxifen $60 \mathrm{mgs}$ (DS) was given twice weekly for three months to all the patients enrolled after assessing Mastalgia, nodularity and lump size at initial and bi-monthly visits. A second cycle of Ormeloxifen $60 \mathrm{mgs}$ once weekly was given to the patients in whom the lumps didn't regress completely at the end of 12 weeks. Visual Analog scale was used for subjective pain assessment and Lucknow Cardiff scale [6] was used for objective nodularity assessment. A significant improvement of aberration of development and cyclical changes of Breast such as cyclical and non-cyclical mastalgia, cyclical nodularity and Fibroadenoma were documented following Ormeloxifen therapy in our study. But the efficacy of Ormeloxifen is doubtful in aberration of involution of breast such as isolated breast macrocysts.

\section{Conclusion}

Ormeloxifen significantly effective in treating the Aberrations of development and cyclical changes of Breast. Its efficacy is not documented in treating Aberrations of involution of breast. It has targeted efficacy profile, avoiding adverse effects. It also provides lower economical burden.

\section{References}

[1]. Hughed LE. Classification of Benign breast disorders., The ANDI classification based on physiological processes within the normal breast. Br Med Bull. 1991 Apr:47(2):251-7

[2]. Srivastava A, Mansel RE, Aravind N, Prasad K, Dhar A, Chabra A, Evidence based management of mastalgia: A meta-analysis of randomized trials. Breast 2007; 16:503-12.

[3]. Sandeep kumar, Ruchi rai, G.G. Agarwal et al; A randomized double-blind placebo controlled trial of ormeloxifen in breast pain and nodularity, The National Medical Journal of India ; vol.: 26, No.: 2, 2013

[4]. B.Lawrence Riggs, M.D., and Lynn C. Hartmann, M.D ., Selective estrogen receptor modulators- mechanisms of action and application to clinical practice ., The New England Journal of Medicine 348(12): 1192 ., February 2003

[5]. M.M.Singh ., Centchroman, a selective estrogen receptor modulator, as a contraceptive and for management of hormone related clinical disorders., Volume 21, Issue 4, July 2001, pages 302-347 Wiley online Library

[6]. Sandeep kumar, Ruchi rai et al., Visual analogue scale for assessing breast nodularity in non-discrete lumpy breasts: the Lucknow Cardiff breast nodularity scale; The Breast June 2010, Vol 19(3): 238-242. 